\title{
Research of composite fuels thermophysical properties based on low-grade coals with addition of fine sawdust and flour industry wastes
}

\author{
Stanislav Yankovsky ${ }^{1,}$, Anton Tolokolnikov ${ }^{1}$, Alexander Matveev ${ }^{1}$, and Yana Marysheva ${ }^{1}$ \\ ${ }^{1}$ National Research Tomsk polytechnic university, 634050 Tomsk, Russia
}

\begin{abstract}
Experimental studies have been carried out to determine the energy and technical characteristics of composite fuels from coal grade 3B (Balakhtinskoye deposit), fine waste and flour from the milling industry. An effective concentration of $50 \% / 50 \%$ composite fuel has been established without the addition of a flour component, in which the combustion heat is reduced by less than $8 \%$, with the flour component added up to $15 \%$, the heat of combustion further decreases less than $2 \%$ of the heat of combustion of homogeneous coal. At the same time, the ash content is reduced to $11 \%$, the yield of volatile components remains at the concentration level of the composite fuel of coal and wood. It is established that this component composition of three types of fuel is suitable for the formation of fuel briquettes suitable for burning in furnaces of small power boilers.
\end{abstract}

\section{Introduction}

It is known [1-4], that coal is a basic fuel for power generation in small-scale power engineering [4-5]. Significant expenditures of funds for its supply to remote regions of the Russian Federation lead to an increase in final cost of energy resources in two or more times, depending on territorial location [5-8]. In this case, the use of local resources in the form of solid composite fuel made of low-grade coals with addition of waste from timber industry and impurities of flour waste as binder is promising for the near future. Studies in these areas are actively conducted; their results are published in papers [1-8]. But results of [1-8] are not the basis for analyzing dependencies of composite fuels thermophysical properties based on low-grade coals with addition of fine sawdust and flour industry wastes. Analysis of composite fuels formation with operational and energy characteristics close to homogeneous coal, but with high environmental parameters is relevant. The goal is experimental determination of binder proportion influence on composite fuel characteristics.

\section{Experimental results and discussion}

\footnotetext{
*Corresponding author: jankovsky@tpu.ru
} 
Technical and energy characteristics of three composite fuels have been determined experimentally [9-10]. Samples of 3B grade coal (Balakhtinskoe deposit, particle size less than 80 microns), fine sawdust and flour industry waste (particle size less than 200 microns) were mixed in different volume concentrations in a galvanized drum of Pulverisette 6 planetary mill with spherical grinding bodies with $5 \mathrm{~mm}$ diameter at required volume ratios. Mixing process was being conducted for 7 minutes at rotation speed of 500 rpm [10].

Concentration compositions are presented in Table 1.

Table 1. Concentration compositions of composite fuels.

\begin{tabular}{|c|c|c|c|}
\hline Fuel & \multicolumn{3}{|c|}{ Concentration, \%o } \\
\hline 3B brown coal & 47.5 & 45 & 42.5 \\
\hline Fine sawdust & 47.5 & 45 & 42.5 \\
\hline Flour waste & 5 & 10 & 15 \\
\hline
\end{tabular}

Figure 1 presents energy characteristics of fuels' main components. Experimentally obtained dependences of composite fuel heat of combustion on its composition are presented in Figures 2-3.

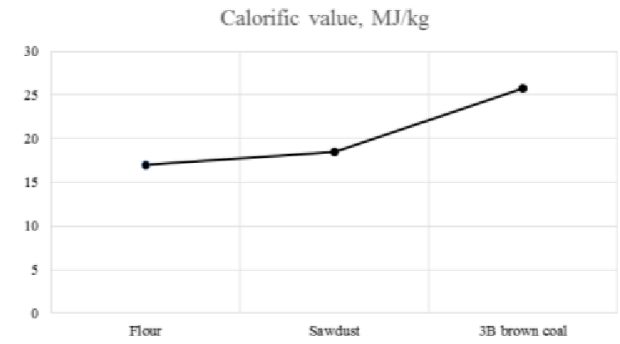

Fig. 1. Calorific content of each component of composite fuel.

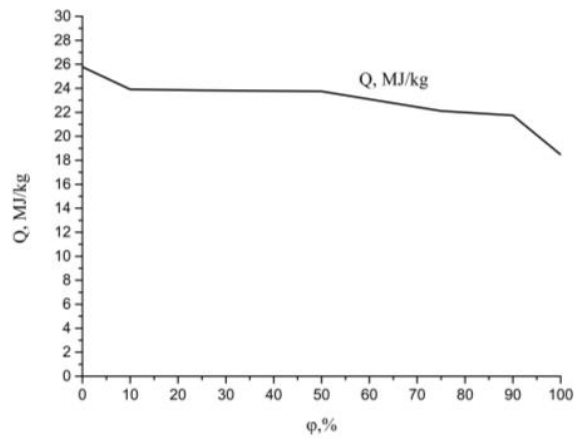

Fig. 2. Sawdust concentration effect on calorific value of composite fuel in relation to homogeneous coal ( ${ }^{\varphi}$ - sawdust content). 


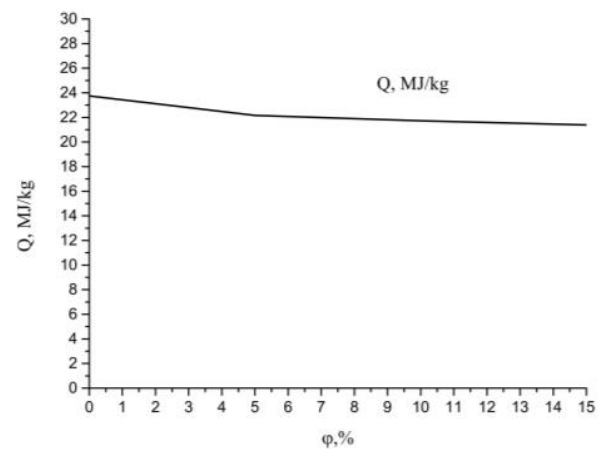

Fig. 3. Flour concentration effect on calorific value of composite fuel in relation to mixture composition of coal and sawdust $50 \% / 50 \%$ ( ${ }^{\varphi}$ - flour content).

Analysis of the results shown in Figure 2 allows determining optimal concentration composition of composite fuel made of coal and sawdust in a ratio of $50 \% / 50 \%$, in which the reduction in calorific content is less than $8 \%$.

Figure 3 illustrates that increase of flour concentration to $5 \%$ in composite fuel reduces its calorific value by less than $6.7 \%$, but addition of $15 \%$ of flour reduces calorific content by $10 \%$.

Figure 4 provides dependence of change in fuel ash content with an increase of flour industry waste concentration.

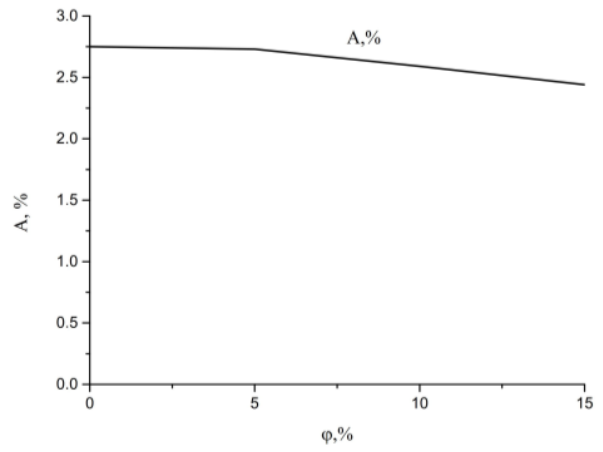

Fig. 4. Flour concentration effect on composite fuel ash content in relation to mixture composition of coal and sawdust $50 \% / 50 \%$ ( ${ }^{\varphi}$ - flour content)

Figure 4 shows that with an increase in flour concentration to $5 \%$ ash content decreases by less than $6 \%$; at concentration of $15 \%$ of flour products in composite fuel ash content is reduced to $11 \%$.

Dependence of composite fuel volatiles yield from its composition is shown in Figure 5. 


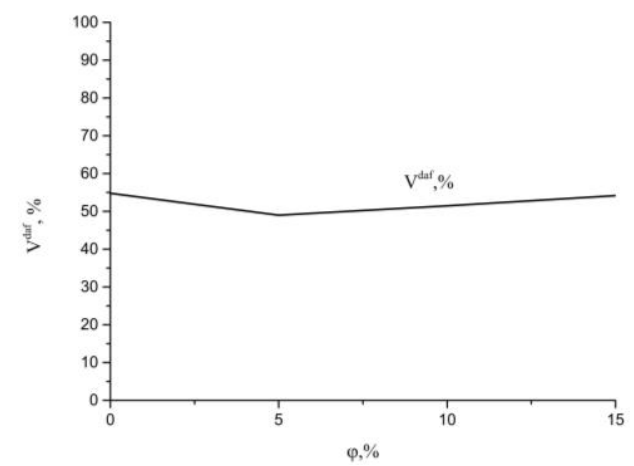

Fig. 5. Flour concentration effect on composite fuel volatiles yield in relation to mixture composition of coal and sawdust $50 \% / 50 \%\left({ }^{\varphi}\right.$ - flour content)

Analysis of volatiles yield dependence suggests that an increase of flour concentration in composite fuels does not lead to significant changes.

\section{Conclusion}

As a result of conducted experiments, it was determined that influence of flour industry wastes concentration is insignificant. Energy and technical characteristics of composite fuels are reduced by less than $10 \%$. As a result of the foregoing, it can be assumed that this component compound is suitable for fuel briquettes formation by cold pressing, suitable for combustion in furnaces of small-scale energy boilers.

The research has been accomplished with financial support of the Russian Federation Ministry of Education and Science within implementation of the project No 13.7644.2017/BCH.

\section{References}

1. K. Y. Vershinina, Scientific Journal, 90, 1(2017)

2. M Jumoke, Applied Energy, 188, 215-225 (2017)

3. A.V. Fedyukhin, I.L. Maikov, V.A. Sinelshchikov, Book of Abstracts of International Conference on Interaction of Intense Energy Fluxes with Matter, 114 (2011)

4. W. Yan, S. Wang, D.G. Zhou, C. Xing, Y. Zhang, G.M. Pharr, Wood and fiber science, 44, 1 (2009)

5. A.G. Korotkikh, K.V. Slyusarskiy, K.B. Larionov, V.I. Osipov, J. Phys. 754, 5 (2016)

6. A.A. Abramovskikh, U.A. Ulyanova, S.V. Lavrinenko, A.A. Matveeva, D. Malishev, MATEC Web Conf. 91, 01002 (2016)

7. N. Galashov, S. Tsibulskiy, A. Kiselev, MATEC Web Conf. 72, (2016)

8. M.P. Baranova, V.A. Kulagin, Fiziko-khimicheskiye osnovy polucheniya toplivnykh vodougol'nykh suspenziy (Monograph, Siberian Federal University, 2011) [In Russian]

9. K. Larionov, I. Korjashov, S. Jankovskij, V. Gubin, A. Zenkov, MATEC Web Conf. 37 (2015)

10. A. Zenkov, S. Yankovsky, A. Matveeva, S. Lavrinenko, A. Gromov, MATEC Web Conf. 01131 (2016) 